\title{
Chapter 25: Learning Analytics: Layers, Loops and Processes in a Virtual Learning Infrastructure
}

\author{
Ruth Crick
}

Institute for Sustainable Futures, University of Technology Sydney, Australia

Department of Civil Engineering , University of Bristol, United Kingdom

DOI: $10.18608 /$ hla17.025

\begin{abstract}
This chapter explores the challenges of learning analytics within a virtual learning infrastructure to support self-directed learning and change for individuals, teams, organizational leaders, and researchers. Drawing on sixteen years of research into dispositional learning analytics, it addresses technical, political, pedagogical, and theoretical issues involved in designing learning for complex systems whose purpose is to improve or transform their outcomes. Using the concepts of 1) layers - people at different levels in the system, 2) loops - rapid feedback for self-directed change at each level, and 3) processes - key elements of learning as a journey of change that need to be attended to, it explores these issues from practical experience, and presents working examples. Habermasian forms of rationality are used to identify challenges at the human/data interface showing how the same data point can be apprehended through emancipatory, hermeneutical, and strategic ways of knowing. Applications of these ideas to education and industry are presented, linking learning journeys with customer journeys as a way of organizing a range of learning analytics that can be collated within a technical learning infrastructure designed to support organizational or community transformation.
\end{abstract}

Keywords: Complexity, learning journeys, infrastructure, dispositional analytics, self-directed learning

Learning analytics (LA) is a term that refers to the use of digital data for analysis and feedback that generates actionable insights to improve learning. LA feedback can be used in two ways: 1) to improve the personal learning power of individuals and teams in self-regulating the flow of information and data in the process of value creation; and 2) to respond more accurately to the learning needs of others. The growth of new types of datasets that include "trace data" about online behaviour; semantic analysis of human online communications; sensors that monitor "offline" behaviours, locations, bodily functions, and more; as well as traditional survey data collected from individuals, raises significant challenges about the sort of social and technical learning infrastructures that best support processes of improvement, adap- tation and change. These challenges are located at the human/data interface and are as important for schools or universities whose purpose is to enhance learning and its outcomes as they are for corporate organizations whose purpose is the provision of a service or a product. Both depend on the capability of humans within their systems to be able to monitor, anticipate, regulate, and adapt productively to complex, rapidly flowing information and to utilize it in their own learning journey to achieve a purpose of value. Learning analytics provides formative feedback at multiple levels in an organization: the same datasets can be aggregated for individuals, teams, and whole organizations. When learning analytics are aligned to shared organizational purposes and embedded in a participatory organizational culture, then new 
models of change emerge, driven by internal agency and agility, rather than by external regulation.

This chapter reports on a sixteen-year research program of dispositional learning analytics that provided a rich experience in the technical, philosophical, and pedagogical challenges of using data to enhance self-regulated learning at all levels in an organization, rather than simply for "top down" decision making. It utilizes the metaphor of a "learning journey" as a framework for connecting different modes of learning analytics that together constitute a virtual learning ecology designed to serve a particular social vision. Drawing on systems thinking, it uses the themes of "layers," "loops," and "processes" as characteristics of complex learning infrastructures and as a way of approaching the design of learning analytics (Blockley, 2010).

\section{LEARNING ANALYTICS FOR FORMA- TIVE ASSESSMENT OF LEARNING}

The challenge of assessing learning dispositions was the starting point for the research program that began in 2000 at the University of Bristol in the UK. Its rationale was drawn from two findings from earlier research: 1) that data identified and collected for assessment purposes drives pedagogical practice; and 2) that high-stakes summative testing and assessment depresses students' motivation for learning and drives "teaching to the test" (Harlen, 2004; Harlen \& Deakin Crick, 2002, 2003). This was a design fault in education systems that have changed little over the last century but that aspire to prepare students for life in the age of "informed bewilderment" (Castells, 2000). The challenge for the research program was first to identify, then to find a way to formatively assess, the sorts of personal qualities that enable people to engage profitably with new learning opportunities in authentic contexts when the "outcome was not known in advance" (Bauman, 2001).

Drawing on a synthesis of two concepts -1) learning power (Claxton, 1999) and 2) assessment for learning (Broadfoot, Pollard, Osborn, McNess, \& Triggs, 1998) - the original factor analytic studies identified seven "learning power" scales and the computation of new variables through which to measure them. These scales included aspects of a person's learning that are both intra-personal as well as inter-personal, drawing on a person's story and cultural context (Wertsch, 1985). Designed as a practical measure, together they were referred to as "dimensions of learning power" (Yeager et al., 2013). The scales were validated with school age students (Deakin Crick, Broadfoot, \& Claxton, 2004; Deakin Crick, McCombs, Broadfoot, Tew, \& Hadden,
2004; Deakin Crick \& Yu, 2008) and with an adult population (Deakin Crick, Haigney, Huang, Coburn, \& Goldspink, 2013) and in 2014 the accumulated data $(<70 \mathrm{~K})$ was re-analyzed to produce a more rigorous and parsimonious instrument, known as the Crick Learning for Resilient Agency Profile (CLARA; Deakin Crick, Huang, Ahmed Shafi, \& Goldspink, 2015).

The purpose of the research was to collect data for teachers that would enable them and their students to understand and optimize the processes of learning: specifically to hand over responsibility for change to students themselves by providing them with formative data and a language with which to develop actionable insights into their own learning journeys. The team used technology to generate immediate personalized feedback from the survey data through computing and representing the dimensions of learning power as a spider diagram. This immediate, visual analytic presents the learning power latent variable scores as a pattern to invite personal reflection. Numerical scores are avoided because they represent a form of analytic rationality (Habermas, 1973) more often used to grade and compare for external regulation and encourage entity thinking rather than integral and dynamic thinking (Morin, 2008). The visual analytic provides a framework and a language for a coaching conversation that moves between the individual's identity and purpose and their learning goals and experiences. It provides diagnostic information to turn self-diagnosis into strategies for change (see Figure 25.1). This later became part of the definition of learning analytics (Long \& Siemens, 2011; Buckingham Shum, 2012).

Since the first studies were completed, ongoing research explored learning and teaching strategies that enable individuals to become responsible, self-aware learners by responding to their Learning Power profiles (Deakin Crick \& McCombs, 2006; Deakin Crick, 2007a, 2007b; Deakin Crick, McCombs, \& Haddon, 2007). The focus was on those factors that influence learning power and the sorts of teaching cultures that develop it (Deakin Crick, 2014; Deakin Crick \& Goldspink, 2014; Godfrey, Deakin Crick, \& Huang, 2014; Willis, 2014; Ren \& Deakin Crick, 2013; Goodson \& Deakin Crick, 2009; Deakin Crick \& Grushka, 2010). Further empirical studies identified pedagogical strategies that support learning power: coaching for learning (Wang, 2013; Ren, 2010), authentic pedagogy (Deakin Crick \& Jelfs, 2011; Huang, 2014), teacher development (Aberdeen, 2014), and enquiry-based learning (Deakin Crick, Jelfs, Huang, \& Wang, 2011; Deakin Crick et al., 2010). The conceptual framework provided by the dimensions of learning power provides specificity, assessability, and thus practical rigour to an otherwise conceptually and empirically complex social process. 


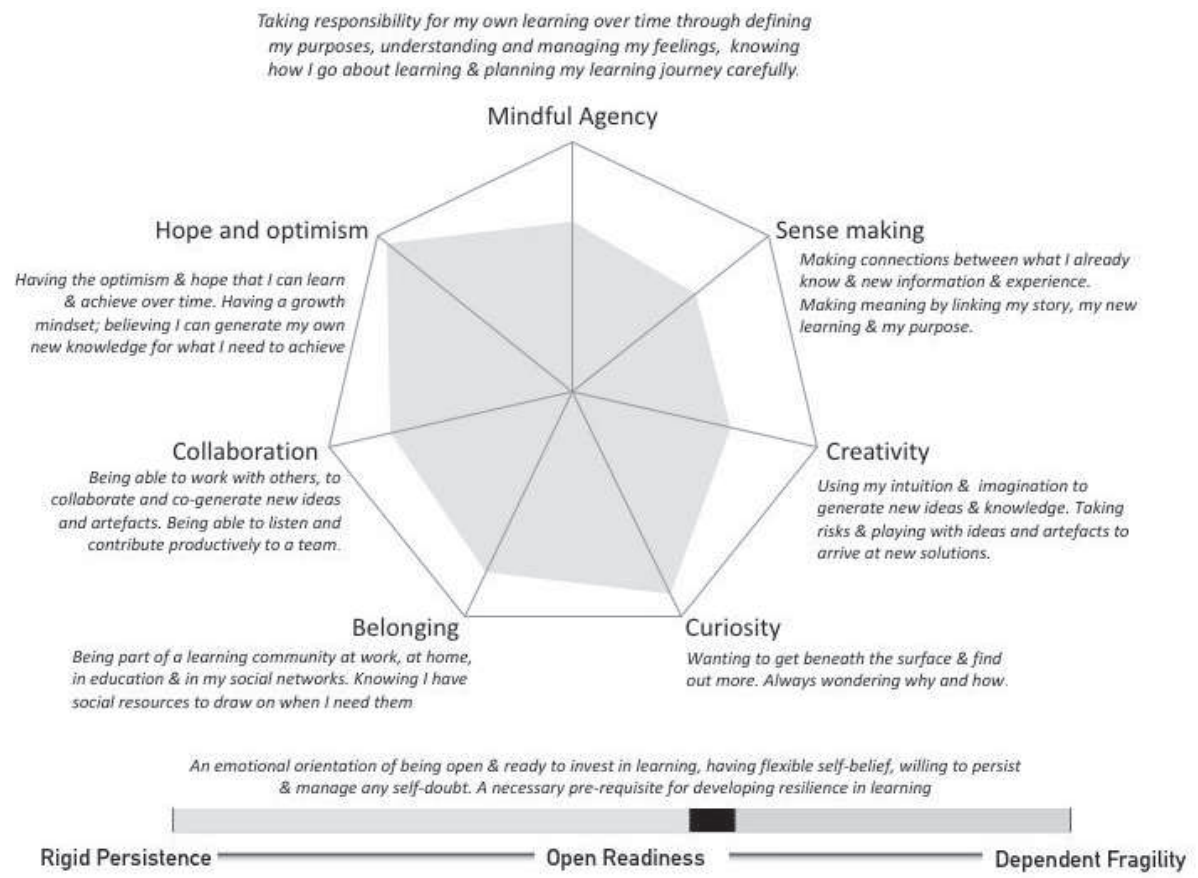

Figure 25.1. Individual Learning Power Profile visual analytic.

The provision of the survey and the calculation of the latent variables in a web-based format afforded the possibility of using the same dataset for rapid feedback for users at four different levels in organizations. First, individual feedback via the visual analytic is available privately to the individual. Second, anonymized mean scores for groups are computed so that a teacher or facilitator can look at the learning characteristics of a teaching group or class and adapt their pedagogy accordingly. Third, anonymized mean scores combined with other variables from an organization's management information system, such as demographics and grouping variables, and others such as attainment or well-being measures, allow for a more sophisticated exploration of data in a whole cohort or organization to inform leadership decision making. Finally, with appropriate permissions, anonymized data can be harvested for exploratory research at a systems level. Each feedback point provides data that carries actionable insights - in other words new learning opportunities (see Figure 25.2).

Rapid feedback of personal data about learning forms part of the emerging field of dispositional learning analytics (Buckingham Shum \& Deakin Crick, 2012). It transgresses traditional boundaries, not only in social science, where the focus for research purposes is often on one variable at a time with a view to exploring the impact of one entity on another to serve a research purpose. Traditional boundaries are also transgressed in terms of data systems, which are often understood as the province of system leaders

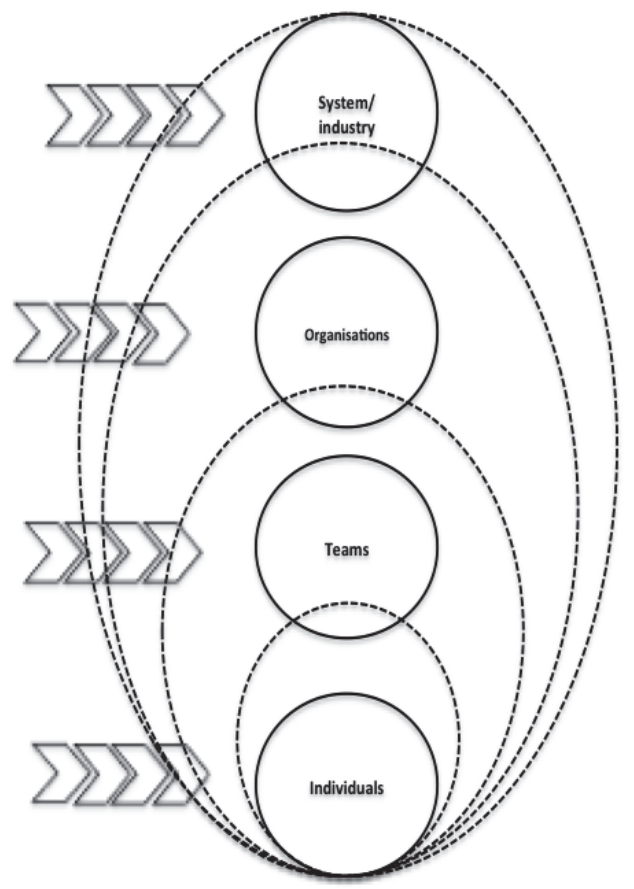

Figure. 25.2. Rapid analytics feedback at four levels.

rather than for empowering subjects themselves to become self-directed learners. Traditionally, data is collected for system leaders rather than for individuals. The infrastructure for gathering data at scale, managing stakeholder permissions, and providing a range of analytics from real time summaries to ex- 
ploratory research has raised challenges in terms of technology, the politics of power, organizational learning agility, and personalization.

\section{LEARNING ANALYTICS AND PEDAGOGY: POINTS OF TENSION}

This research program served a practical purpose in the development of pedagogies for personalization and engagement in a variety of educational and corporate settings. The term "dispositional learning analytics" was not used in until as late as 2012 (Buckingham Shum \& Deakin Crick, 2012) and the focus on learning analytics was an "unintended outcome" of the original program. The unique interactions between technology, computation, and human learning combined over time to make this approach powerful, sustainable, and scalable in a way that was not possible in assessment practices until the emergence of technology. These interactions are crucial to understanding and developing the emerging field of learning analytics since they also raise significant challenges as well as opportunities.

Perhaps the most significant challenge is in the intrinsic transdisciplinarity of this approach and the need for quality in three different fields - social science, learning analytics, and practical pedagogy, the last of which is highly complex and engages with many forms of human rationalities and relationships. The information explosion has changed forever the ways in which humans relate to information and this adds more complexity (Morin, 2008). These affordances and challenges will be addressed in the next section.

\section{Visual Representation of Data: Making the Complex Meaningful}

The presentation of a latent variable in data representing how a person responds to a self-report questionnaire about their learning power is complex. Learning power itself is described as "an embodied and relational process through which we regulate the flow of energy and information over time in the service of a purpose of value" (Deakin Crick et al., 2015, p. 114). For data to be useful to the individual in this context, it needs to be meaningful but sufficiently complex and open to allow for interpretation and response in an authentic context. The goal of learning power assessment is to develop people as resilient agents able to respond and adapt positively to risk, uncertainty, and challenge. As Rutter (2012) argues, the meaning of experience is what matters in resilience studies; resilience is an interactive, "plastic" concept, a state of mind, rather than an intelligence quotient or a temperament. Thus the form in which data about a person's resilient agency is presented to them needs to be fit for this purpose - sufficiently robust to be reliable and valid in traditional terms but sufficiently open-ended and flexible to be "recognized" and responded to in a particular context. The visualization of the spider diagram achieves this goal of being precise enough whilst maintaining a representation of complexity, plasticity, and provisionality. The absence of numbers on the spider diagram is significant since in Western culture a number is often interpreted as an "entity" and not a "process" and can lead to a "fixed" rather than "growth oriented" mindset (Dweck, 2000). Technology makes the visualization of data more effective.

A further observation about the visualization of learning power data is that it connects with different ways of knowing or different "deep seated anthropological interests" (Habermas, 1973, 1989; Outhwaite, 1994). Habermas describes these as "empirical analytical interests," "hermeneutical interests" and "emancipatory interests." Reflecting on "my learning power" begins with a focus on learning identity - Is this like me? Am I this sort of learner? What is my purpose? How do I want to change? These questions connect with emancipatory rationality, or the drive for "autonomy" (Deci \& Ryan, 1985) and these forms of rationality are simply not amenable to interpretation through "standardization" since each human being is unique. At best they may be represented through archetypes (Jacobi, 1980).

\section{Image: Metaphor and Story as Carriers of Data}

A ubiquitous finding from the studies has been the use of metaphor, story, and image to communicate the meaning of the learning power dimensions and to enable communal dialogue and sense-making. Most notable was the creation of a community story over a year in an Australian Indigenous community. The story was co-constructed with key characters as (sacred) animals that the community had chosen to represent each learning power dimension (latent variable) that they encountered via the learning analytic. The animals locked in Taronga Zoo combined their learning powers to plan a breakout. The story articulated the community's unique cultural history of oppression whilst opening up opportunities for engaging in forms of $21^{\text {st }}$-century learning as equals in a new paradigm (Goodson \& Deakin Crick, 2009; Deakin Crick \& Grushka, 2010; Grushka, 2009). Figure 25.3 is an example of one of the graphics represented and used in that context: a representation of a wedgetailed eagle, which was one of the outcomes of months of community dialogue and debate, before being finally ratified by the local elders. A detailed discussion of this project is beyond the scope of this chapter. The point is that community sense-making, aligned with technology and dispositional analytics, can be represented by images or visualizations, which are locally empowering because they connect with deeper forms 
of narrative and tradition. Thus they enable educators to engage profitably and meaningfully - and in a time-relevant manner - with the "perezhivanie" - the lived experiences of communities (John-Steiner, 2000; John-Steiner, Panofsky, \& Smith, 1994).

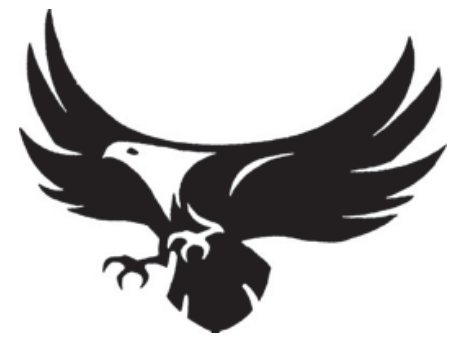

Figure. 25.3. A visual graphic representing "strategic awareness.'

(C) Black Butterfly Designs

\section{One Data Point and Different Ways of Knowing}

An individual produces a learning power self-assessment survey with rapid feedback designed to stimulate self-directed change. The emancipatory rationality for reflection on self and identity required will often take the form of narrative: it's unique, polyvalent, time bound, and "open-ended" (Brueggemann, 1982). When that individual uses the same data to develop a strategy for moving forwards and achieving a learning purpose, then they are likely to be using "interpretive rationality" or, in Habermasian terms, "hermeneutical rationality." They will be reflecting on a goal and making judgments about the best way to achieve it, collating qualitative data, collaborating with others and drawing on existing funds of knowledge. If they then develop a "measurement model" so that they are able to judge whether they have achieved their purpose, then they will use empirical/strategic rationality - using analytical, means-end logic to determine whether they have succeeded in their purpose.

Thus one useful data point can be apprehended through different rationalities or ways of knowing when it is harnessed to a personal or social purpose. When data is aggregated and anonymized, teachers or facilitators can evaluate and analyze the data quantitatively to assess whether their pedagogy is achieving its purpose, and interpret their findings in order to improve and adjust what they do. Here the same forms of rationality are in operation at an organizational level but the focus shifts to hermeneutical and strategic rationality in the service of a shared purpose. The data is used for leadership decision making. At a systems level, when the same accumulated data is analyzed in a way that is abstracted from context, then the modus operandi is predominantly strategic/analytical rationality.

\section{Rapid Feedback at Multiple Levels: Criti- cal for Ownership and Improvement}

Technology enables easy collection, automatic computation, and rapid feedback of survey data to users at different levels in organizations. Where an organization enables self-managing teams to operate in pursuit of shared organizational purpose (Laloux, 2015) then rapid feedback of data that informs both process and outcome is a crucial resource. For example, in a learning organization such as a school or college, a shared purpose is that students develop lifelong learning competences. In this case, CLARA data can be owned and used for improvement by students themselves, by teachers who want to evaluate how effectively their pedagogy is producing lifelong learning competences, by leaders in making decisions about overall college policy in relation to these outcomes, and by researchers who explore and analyze the data to produce new knowledge. Two aspects of this are important: first the rapid feedback and second the sense of ownership of data and professionalism that the feedback affords and requires. A time lag is no longer necessary between data collection, analysis, and feedback of survey data. Historically such time lags often meant that feedback arrived too late to change practice in the context in which data was collected. From a practitioner's perspective, the research was "done to them" rather than owned and responded to by them. Closing this lifecycle gap between research and practice is a critical task to which learning analytics makes a significant contribution.

\section{Top Down or Bottom Up?}

Related to this is the sense of participation and ownership in improvement processes that this affords. The authority to interpret the data is aligned with the responsibility to respond to it and improve practice. This has profound implications for societies in which politically defined external regulatory frameworks have become anachronistic and can often work against quality, collaboration, evolution, and transformation. Typically, such frameworks are produced by politicians for accountability purposes and are based on worldview assumptions rooted in the industrial era. Put simply, they often measure the wrong things and the purpose is political accountability and control. So key questions are Who does this data belong to? and Whose purposes are being served? Whilst there is a strong argument for some top-down accountability in learning systems - particularly where young people and public finance are concerned - there is an equally strong argument for empowerment and self-regulation at micro (individual) and meso (organizational) levels. This complexity is a key quality of self-organizing systems that, by definition, require forms of professionalism (commitment to purpose) that go beyond compliance 
with external regulatory frameworks.

Understanding the system as a whole is a key to learning analytics aimed at improvement (Bryk, Gomez, Grunrow, \& LeMahieu, 2015; Bryk, Gomez, \& Grunow, 2011; Bryk, Sebring, Allensworth, Luppescu, \& Easton, 2010). Borrowing from the world of systems thinking in Health and Industry (Checkland, 1999; Checkland \& Scholes, 1999; Snowden \& Boone, 2007; Sillitto, 2015) the rigorous analysis of a system leads to the identification of improvement aims and shared purpose the boundaries of the system are aligned around its purpose (Blockley, 2010; Blockley \& Godfrey, 2000; Cui \& Blockley, 1990). Thus an alignment around purpose at all levels in a system will both require and enable data to be owned at all levels by those responsible for making the change and using data for actionable insights (see Figure 25.4). The power, or the authorship, of decision-making is both inclusive and participatory. Technical systems and analytics need to reflect this.

\section{Practical Data: Fitness for Purpose}

A key issue in learning analytics has to do with the reliability and validity of data, particularly when it is used to judge quality of performance and/or process in authentic contexts. More than ever, quality is an ethical issue. Does this self-assessment tool measure what it purports to measure? Who has the authority to interpret the results? As Yeager et al. (2013) argue, "conducting improvement research requires thinking about the properties of measures that allow an organization to learn in and through practice" (p. 9). They go on to identify three different types of measures that serve three different purposes: 1) for accountability, 2) for theory development, and 3) for improvement. They characterize the latter as practical measures that may measure intermediary targets, framed in a language targeted to specific units of change, contextualized around common experiences and engineered to be embedded in everyday practice. Practical measures may be used for assessing change, for predictive analysis, and for priority setting.

The focus of these practical measures for Yeager and colleagues (2013) is on their use in change programs in organizations led by improvement teams or leadership groups. However, an additional purpose of practical measures is to stimulate ownership, awareness, and responsibility for change on the part of individual users. Practical measures present a theoretical challenge for psychometricians in terms of the need for new summary statistics that contribute to quality assurance where historically much theoretical development has been focused on measures for accountability and theory development, such as internal consistency, reliability, and validity. This issue of authority and responsibility is crucial and one response is to apply a "fitness for purpose" criterion. If the purpose of the measure is to stimulate individual awareness, ownership, and change then the subject of that purpose must have the authority to judge the validity and trustworthiness of the measure since, when it comes to emancipatory rationality and narrative data, the subject is a unique self-organizing system. If the purpose of the measure were to provide government with a measure of success of a policy then the professional community of domain-specific statisticians would have the authority to judge the reliability, validity, and therefore trustworthiness of the data. In both cases, the judgement is about fitness for purpose.

For the emerging field of learning analytics - with its focus on formative feedback for improvement for individuals, teams, and organizations - these issues represent an

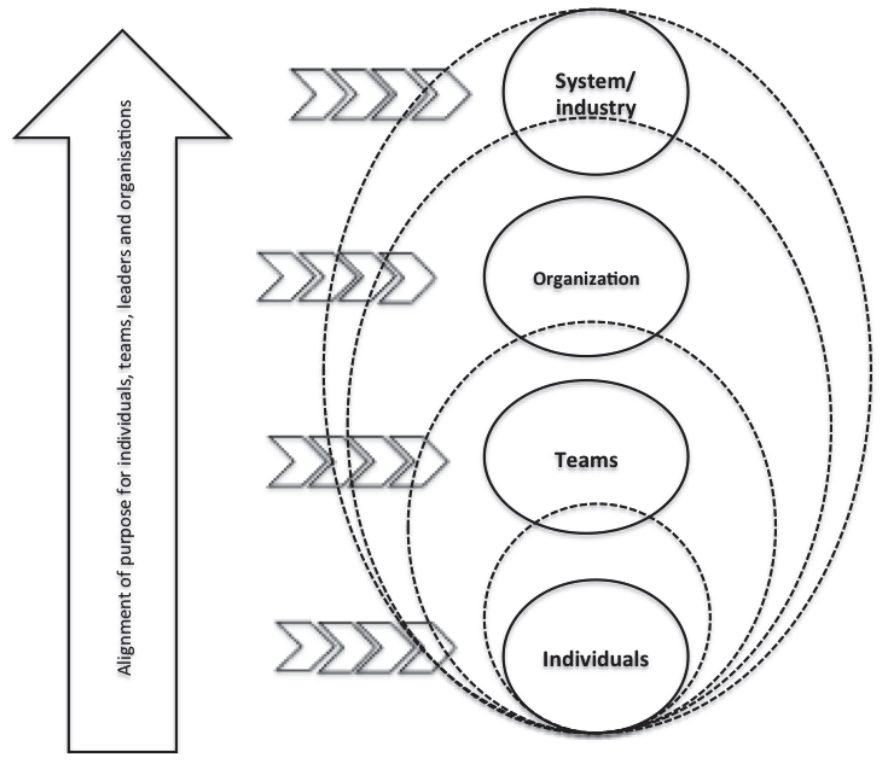

Figure 25.4. Rapid feedback at four levels aligned to organizational purpose. 
important field for development. If an assessment tool sold to an institution has no scientific rigour behind it, then even the most sophisticated technology and modes of delivery will not compensate. On the other hand, an organization might want to serve a small number of questions to its community via a tool such as Blue Pulse $\mathrm{e}^{1}$ as a "sensor mechanism" randomized to test the anonymized views of stakeholders about the direction of particular organizational strategies. How do they select the most useful items? What "weight of evidence" do they ascribe to the subsequent data?

In the context of rapid social and technological change, these issues are common. Tools designed for accountability or theory development often have no practical value and thus limited usefulness as learning analytics, whilst tools designed to support practice and improvement often have no theoretical or empirical rigour. The social and moral challenge for learning analytics is to combine and manage both.

\section{TECHNICAL CHALLENGES}

The focus of this chapter so far has been on one particular dispositional learning analytic, CLARA, and the issues this has raised. However, any survey tool designed as a practical measure to provide rapid feedback of data for improvement purposes will face similar issues. This section focuses on some of the technical challenges that have framed the experience of the learning power assessment community through successive iterations of technical platforms designed to service the tool.

\section{Survey Platforms}

Perhaps because the popular understanding of "surveys" is that they belong to the researchers who administer them, it has been a challenge to build a survey platform to capture data for use at different levels in an organization. The purpose of the data captured in learning analytics is for the subject first, then the facilitator/teacher, then the organization, and finally for researchers, whose brief is to research the whole process or undertake blue skies research on the resultant anonymized datasets. This is because learning can only be done by the learner themselves (Seely Brown \& Thomas, 2009, 2010; Thomas \& Seely Brown, 2011). This turns the traditional research survey platform on its head. The biggest challenge lies in data protection and ethics and the need for the platform to perform the following functions:

1. Know the identity of each user in order to provide personalized feedback and save that identity for matching with other variables.

2. Protect users at higher "levels" in the organization

${ }^{1}$ www.eXplorance.com from the knowledge of the ID of each user whilst matching teachers and students (or employees and managers) where appropriate.

3. Harvest and store anonymized data for research purposes across projects.

What is critical is the underlying data structure that needs to link IDs with three types of variables: demographic, grouping, and survey. Without this flexible data structure, the opportunities presented by learning analytics using self-report survey data are severely limited.

Since 2002, learning power research and development teams have prototyped six platforms. The current solution is through a partnership with one of the world's leading survey providers, whose business development strategy is aligned closely with the vision for learning analytics to support the organizational improvement cycle. The Surveys for Open Learning Analytics (SOLA) ${ }^{2}$ platform powered by eXplorance Blue hosts research validated surveys and provides feedback at four levels: for individual users to support personal change; for team leaders to respond more accurately to the learning needs of their groups; for organizational leadership decision making and for systems-wide analysis and research. Examples of feedback at each level are presented in the Appendices.

\section{Collaborative Business Models}

This form of collaboration raises issues about the "ownership" of the model amongst the stakeholders who have an interest in it and the management of intellectual property. These include researchers, practitioners, policy makers, and business - both the "education and training" business and the "technology" business. Developing platforms capable of realizing the potential of learning analytics requires business models capable of supporting collaboration, evolution, and innovation and meeting the needs of diverse stakeholders. The interests of different parties have to be balanced in a way that serves the common good, rather than permitting, say, commercial interests to "colonize" research interests, or practitioner interests to "colonize" technical interests. A key factor is the typical lifecycle needs of these differing stakeholders that have to be understood and "harmonized" in order for each to benefit over time. ${ }^{3}$

\section{Identity Management}

ID management is a key factor for the learning analytics included in wider virtual ecologies for learning. The challenges of ID management are fundamentally

${ }^{2}$ www.learningemergence.com

${ }^{3}$ The Learning Emergence network that crowd-sourced the funds for the SOLA platform formed a Limited Liability Partnership in the UK as a vehicle to provide this level of flexibility, linking research, enterprise, and practice around the world: www.learningemergence.com 
ethical in nature - protecting individuals' personal data, providing feedback that is personal and supported in appropriate ways through coaching and learning relationships where needed whilst enabling stakeholders at different levels in the system to access anonymized data where they have permission and to match datasets where that is required by research, so as to explore the patterns and relationships between variables in complex learning infrastructures.

Apart from surveys, many tools are learning analytics in the sense that they provide formative feedback for individuals to support their learning in some way. For example, the Assessment of Writing Analytics being developed by (Selvin \& Buckingham Shum, 2014) or the iDapt ${ }^{4}$ tool for reflexive understanding of an individual's mental models that shape their approach to their professional task (Goldspink \& Foster, 2013). The former is a way of critiquing and supporting individuals in developing academic argumentation as a part of their knowledge generation whilst the latter addresses issues of identity and purpose through repertory grid analysis (Kelly, 1963). These are both critical aspects of learning journeys whose focus is on feedback for awareness, ownership, and responsibility for the process of learning on the part of the individual.

\section{LEARNING ANALYTICS AND LEARNING JOURNEYS}

Using learning analytics to stimulate change in learning power inevitably invites questions about the wider ecology of processes and relationships that can empower individuals to adapt profitably to new learning opportunities. This is particularly important in authentic contexts where the outcome is rarely known in advance. The metaphor of a "learning journey" was adopted to reflect the complex dynamics of a learning process that begins with forming a purpose and moves iteratively towards an outcome or a performance of some sort. Learning power enables the individual or team to convert the energy of purpose into the power to navigate the journey, to identify and select the information, knowledge, and data they need to work with to achieve that purpose (see Figure 25.5; Deakin Crick, 2012). When an individual or a team learns something without reflecting on the process of learning at a meta-level, this is "single loop" learning. Double loop learning is when the individual or team is able "reflexively to step back" from the process and learn how to learn with a view to improving the process and doing it more effectively next time. They are intentionally becoming more agile and responsive in regulating the flow of information and data that they need to achieve their purpose.
This framework provides a useful model through which to understand the sort of learning infrastructure and the analytics to support learning and improvement. It provides a typology for learning analytics tuned to support learning and, critically, to enable learners to step back from the "job they are doing" to reflect at a meta-level, to monitor, anticipate, respond, and learn - in other words to engage in double loop learning (Bateson, 1972; Bruno, 2015) as depicted in Figure 25.6.

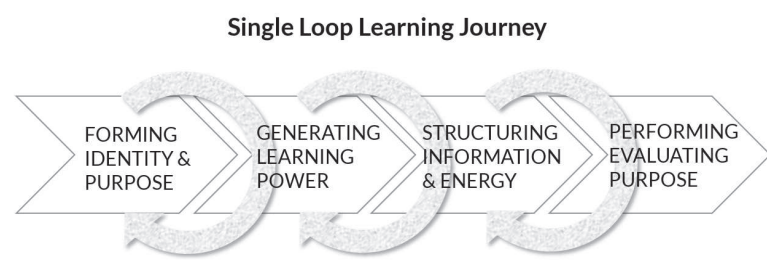

Figure. 25.5. A single loop learning journey.

The Four Processes of a Learning Journey A learning journey is a dynamic whole with distinguishable sub-processes. It has a natural lifecycle and is collaborative as well as individual, personal as well as public. Learning journeys happen all of the time at different levels and stages. Learning is framed by a purpose, an intention, or a desire that provides the "lens" through which the individual or team can identify and focus on the information that matters. Articulating purpose is the first stage of the "meta language" of learning. Without purpose, learning lacks direction and discipline and it is difficult to select from a welter of data the information that really matters. Developing personal learning power through which to articulate a purpose and respond to data is the second process. The third is the structuring and re-structuring of information necessary to achieve the particular purpose. The final process is the production and evaluation of the product or performance that achieves the original the purpose.

A learning journey is an intentional process through which individuals and teams regulate the flow of energy and information over time in order to achieve a purpose of value. It is an embodied and relational process, which can be aligned and integrated at all levels in an organization, linking purpose with performance and connecting the individual with the collective. The learning power of individuals and teams converts the potential energy of shared purpose into change and facilitates the process of identifying, selecting, collecting, curating, and constructing knowledge in order to create value and achieve a shared outcome.

${ }^{4}$ www.inceptlabs.com.au 


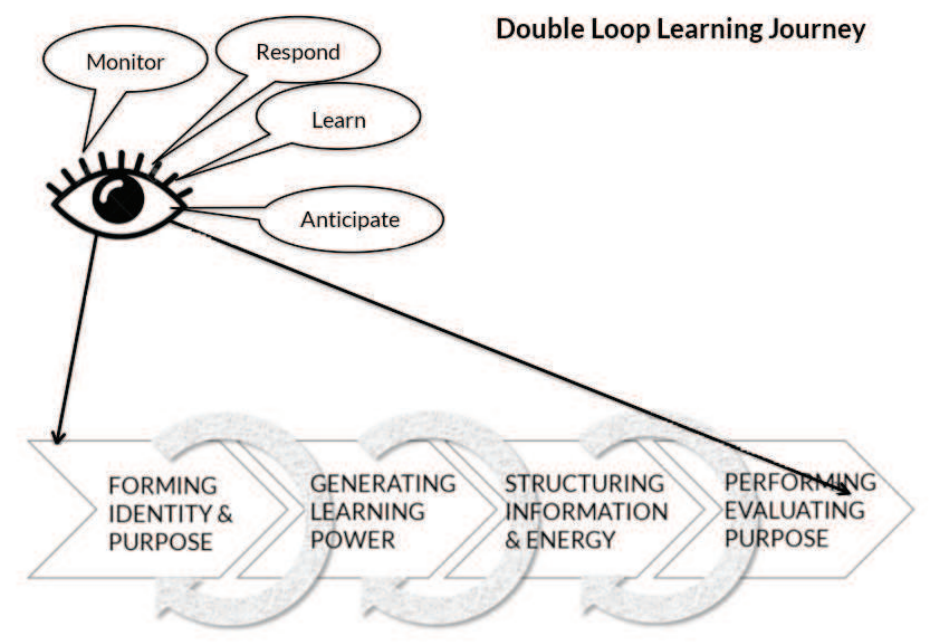

Figure 25.6. Double loop learning journeys.

\section{Learning Journeys as Learning Infrastructure}

It is no longer sensible or even possible to separate the embodied and the virtual in learning. The future is both intensely personal and intensely technological. The challenge is to align social and personal learning journeys with the sorts of technologies and learning analytics that serve them and scaffold intentional "double loop" learning.

A learning journey has a generic architecture: it has stages that occur in a sequence, a start event, a finish event, and many transition events in between. It covers a particular domain; it faces inwards as well as outwards; it is framed by user need or purpose. It is iterative and cumulative. It is focused on a stakeholder or customer task and is ideally aligned to organizational target outcomes. Each stage has many "next best actions" and interactions, framed by a meta-movement between purpose and performance. Stakeholders use personal learning power and knowledge structuring tools to navigate their journey. Stages have transition rules and interaction rules and stakeholders can be on many journeys at the same time. A journey can be collaborative or individual, simple or complex, high value or low value. Journeys follow stakeholders across whatever channels they choose and they are adaptive to individual behaviour. They cover different territories with domain-specific sets of knowledge and know-how and they integrate knowing, doing, and being.

There are at least three distinct applications of these ideas for learning analytics:

1. To frame the relational, social, and technical learning infrastructure of an organization so that individuals and teams become more agile, responsive, and able to respond productively to change and innovation
2. To design models that explore and explain stakeholder behaviour - how students or customers embody purpose, learning power, knowledge, and performance in order to communicate more accurately with stakeholder communities

3. To develop digital infrastructure to support self-directed learning and behaviour change, at scale, in particular domains - in other words, mass education, across domains as defined and embracing as, for example, climate change or financial competence

Learning Infrastructure for Living Labs: Learning Analytics for Learning Journeys

To be resourced at scale, learning journeys require a network infrastructure that accesses information and experience from a wide range of formal and informal sources, inside and beyond the organization. The individual or team relates to all of these in identifying, selecting, and curating what they need in terms of 1) information and data and 2) "how to go about it" expertise for achieving their purpose. This network infrastructure is part of a wider ecosystem with platforms that scaffold these relationships drawing on cloud technology, mobile technology, social learning and curating, learning analytics for rapid feedback, "big data" and badges - to name some key analytic genres.

There are strong synergies here with best practices in real-time, omni-channel customer communication management through the recognition that many customer communication journeys are in fact learning journeys. They also involve individuals in engaging with information in order to achieve a purpose (Crick \& MacDonald, 2013).

Providing and servicing this learning infrastructure is a specialist task that is arguably the purpose of a "living lab" or a "network hub" in an improvement 
community. The network (social and organizational relationships) and the ecosystem (technical resources to scaffold these relationships) provide an infrastructure with permeable boundaries between research, policy, practice, and commercial enterprise, facilitating engaged, trans-disciplinary, carefully structured improvement prototypes. Such a "hub" is sometimes described as a "living lab," the purpose of which is to integrate engaged, user-driven improvement research with technology, professional learning, and the wider research community. It provides, and researches, core hub functions and expertise in partnership with the enterprises needed to scale and deliver learning services.

Supporting such a learning infrastructure requires sustained attention to different types of expertise and resource development, including the following:

- $\quad$ The personal and social relationships necessary for facilitating and leading learning journeys including storying, reflection, personal learning power, and purposing

- The organizational arrangements that support learning journeys as a modus operandi for improvement - such as rapid prototyping, coaching, and agile learning cultures

- $\quad$ The architecture of space (virtual and embodied) within the relevant domain of service

- $\quad$ The technologies, tools, and analytics that support the processes of learning journeys through rapid feedback of personal and organizational data for stimulating change, defining purpose, knowledge structuring, and value management

- $\quad$ The virtual learning ecosystem that facilitates and enhances participatory learning relationships across the project/s at all levels - users, practitioners, and researchers

Figure 25.7 presents a high-level design for such a learning journey infrastructure. ${ }^{5}$

\section{A Transition in Thinking}

The idea of a learning journey is simple and intuitive. The metaphor facilitates an understanding of learning as a dynamic process; however, it does represent a fundamental transition in how we understand knowledge, learning, identity, and value. Knowledge is no longer a "stock" that we protect and deliver through relatively fixed canons and genres; it is now a "flow" in which we participate and generate new knowledge, drawing on intuition and experience. Its genres are fluid and institutional warrants are less valuable (Seeley Brown, 2015). Learning power is the way in which we regulate

${ }^{5}$ This high level learning journey infrastructure is derived from customer journey architecture developed in the financial services market by Decisioning Blueprints Ltd. www.decblue.com that flow of energy and information over time in the service of a purpose of value - rather than a way of receiving and remembering "fixed" knowledge from experts. Millennial identity is found not in ownership and control, but in creating, sharing, and "remixing" in agency, impact, and engagement. Value is generated in the movement between purpose and performance. Leadership is about learning our way forward together.

\section{What Next?}

A plethora of candidate tools and platforms use learning analytics to optimize and support learning for individuals and to improve learning contexts. Tools that address reflective writing (Simsek et al., 2015), sense making , coaching, knowledge curation and sharing (www.declara.com), harnessing collective intelligence (Buckingham Shum, 2008; Buckingham Shum \& De Liddo, 2010; Buckingham Shum \& Ferguson, 2010), and leadership decision making (Barr 2014) to name a few.

The big challenge for $21^{\text {st }}$ century learning professionals is understanding how these tools and platforms cohere within a learning organization, a virtual collaboratory or a living lab, in which the focus is on the learning of a whole community of interest, such as those concerned with renewing a city's infrastructure, or a geographical region, or wide domains of public concern such as financial education or climate change. Many of the ideas and learning analytics practices discussed here have been developed and applied in different contexts already. What is required next is a way of integrating these ideas and practices in an authentic and grounded context, focusing on how the whole fits and flows together. This requires a business model for all stakeholders that makes collaboration - not competition - the modus operandi. It requires all stakeholders to abandon "silos" in favour of networks, and be willing to "learn a way forward together," which inevitably also means having permission to fail. In short, these ideas form a starting point for the resourcing of a living lab or network hub, supported by a partnership of core providers constructing coherence from their four contextual perspectives: research, industry, the business world of "learning professionals," and the personal learning of all stakeholders.

\section{CONCLUSION}

This chapter has focused on some of the challenges and opportunities of the use of technology and computation for enhancing the processes of learning and improvement - rather than only the outcomes. Learning analytics and the affordances of technology have become game-changers for sustainability for organizations in a data-rich, rapidly changing world. Learning analytics are designed to provide formative feedback at multiple levels and these can be aggregated 


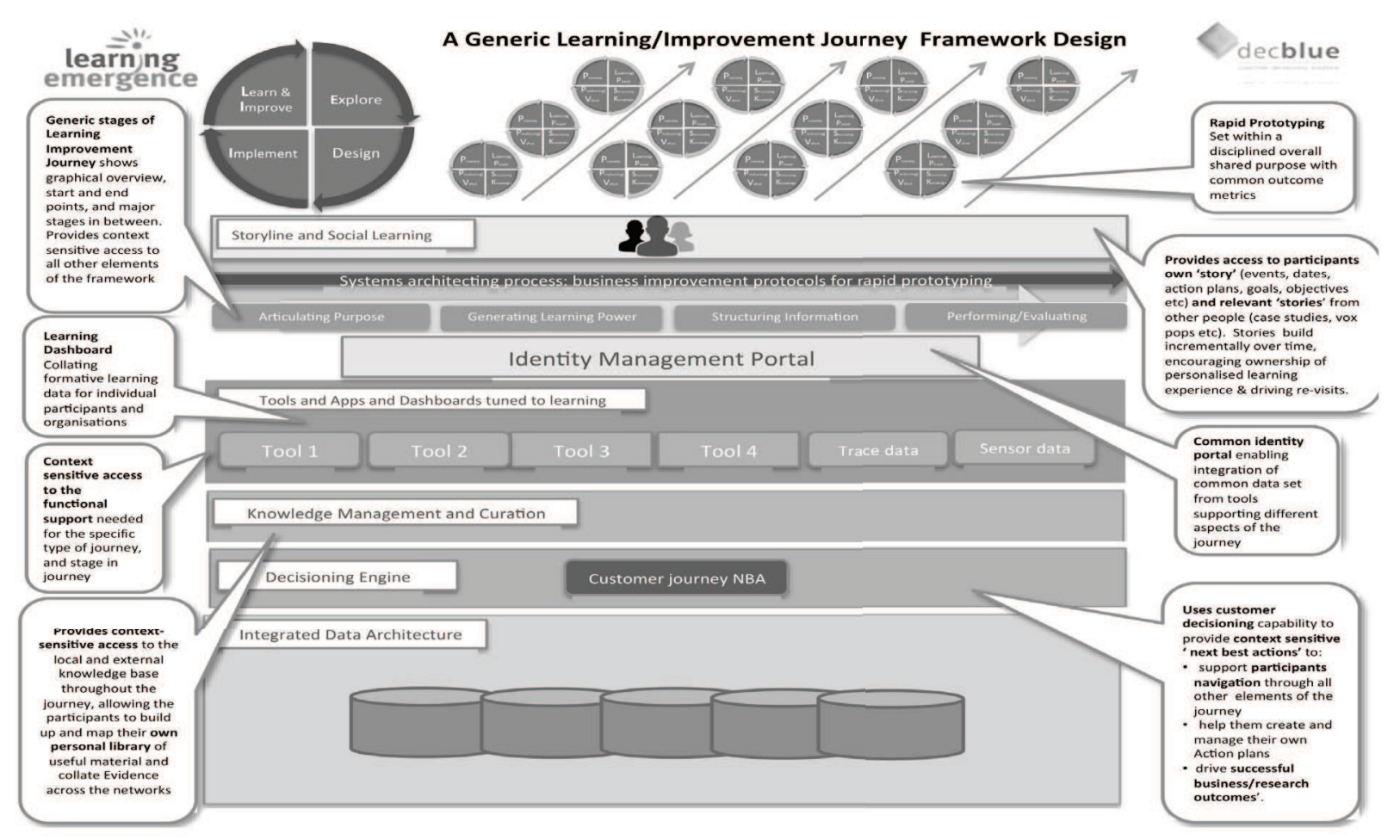

Figure 25.7. High level design for learning architecture.

(C) Decisioning Blueprints Ltd

for individuals, teams, and whole organizations. When learning analytics are aligned to shared organizational purposes and embedded in a participatory organizational culture, new models of change emerge capable of integrating external regulation with internal agency and agility. This chapter began with an account of a learning analytic that focused on generating learning power for individuals. As its research and development program progressed, it became clear that learning power and its associated analytics were just one part of a more complex and dynamic learning journey. The learning journey is a useful metaphor for framing the way we think about and design learning analytics, as part of the sort of learning infrastructure we need to develop, for learning organizations and in wider social contexts such as living labs. The technical, political, commercial, and philosophical challenges are immense and can only be met by thinking and design that account for complexity and participation.

\section{REFERENCES}

Aberdeen, H. (2014). Learning power and teacher development. Graduate School of Education Bristol, UK.

Barr, S. (2014). An integrated approach to decision support with complex problems of management. University of Bristol, UK.

Bateson, G. (1972). Steps to an ecology of mind. San Francisco, CA: Chandler.

Bauman, Z. (2001). The individualized society. Cambridge, UK: Polity Press.

Blockley, D. (2010). The importance of being process. Civil Engineering and Environmental Systems, 27(3), 189-199.

Blockley, D., \& Godfrey, P. (2000). Doing it differently: Systems for rethinking construction. London: Telford.

Broadfoot, P., Pollard, A., Osborn, M., McNess, E., \& Triggs, P. (1998). Categories, standards and instrumentalism: Theorising the changing discourse of assessment policy in English primary education. https://eric. ed.gov/?id=ED421491 
REFPRREANGES(1982). The creative word: Canon as a model for biblical education. Philadelphia, PA: Fortress Press.

Bruno, M. (2015). A foresight review of resilience engineering: Designing for the expected and unexpected. London: The Lloyds Register Foundation.

Bryk, A., Gomez, L., Grunrow, A., \& LeMahieu, P. (2015). Learning to improve: How America's schools can get better at getting better. Harvard, MA: Harvard Educational Press.

Bryk, A., Gomez, L. M., \& Grunow, A. (2011). Getting ideas into action: Building networked improvement communities in education. In M. T. Hallinan (Ed.), Frontiers in sociology of education (pp. 127-162). Springer Netherlands.

Bryk, A., Sebring, P., Allensworth, E., Luppescu, S., \& Easton, J. (2010). Organizing schools for improvement: Lessons from Chicago. Chicago, IL: University of Chicago Press.

Buckingham Shum, S. (2008). Cohere: Towards web 2.0 argumentation. Paper presented at the $2^{\text {nd }}$ International Conference on Computational Models of Argument, 28-30 May 2008, Toulouse, France.

Buckingham Shum, S. (2012). Learning analytics. Moscow: UNESCO Institute for Information Technologies.

Buckingham Shum, S., \& Deakin Crick, R. (2012). Learning dispositions and transferable competencies: Pedagogy, modelling and learning analytics. Proceedings of the 2 nd International Conference on Learning Analytics and Knowledge (LAK '12), 29 April-2 May 2012, Vancouver, BC, Canada (pp. 92-101). New York: ACM.

Buckingham Shum, S., \& De Liddo, A. (2010). Collective intelligence for OER sustainability. Paper presented at the $7^{\text {th }}$ Annual Open Education Conference, 2-4 November 2010, Barcelona, Spain.

Buckingham Shum, S., \& Ferguson, R. (2010). Towards a social learning space for open educational resources. Paper presented at the $7^{\text {th }}$ Annual Open Education Conference, 2-4 November 2010, Barcelona, Spain.

Castells, M. (2000). The rise of the network society, vol. 1 of The information age: Economy, society and culture. Oxford, UK: Blackwell.

Checkland, P. (1999). Systems thinking, systems practice. John Wiley.

Checkland, P., \& Scholes, J. (1999). Soft systems methodology in action. Chichester, UK: Wiley.

Claxton, G. (1999). Wise up: The challenge of lifelong learning. London: Bloomsbury.

Crick, T., \& MacDonald, E. (2013). One customer at a time. Cranfield University.

Cui, W., \& Blockley, D. I. (1990). Interval probability theory for evidential support. International Journal of Intelligent Systems, 5(2), 183-192.

Deakin Crick, R. (2007a). Enquiry based curricula and active citizenship: A democratic, archaeological pedagogy. CitizEd International Conference Active Citizenship, Sydney.

Deakin Crick, R. (2007b). Learning how to learn: The dynamic assessment of learning power. Curriculum Journal, 18(2), 135-153.

Deakin Crick, R. (2014). Learning to learn: A complex systems perspective. In R. Deakin Crick, C. Stringer, \& K. Ren (Eds.), Learning to learn: International perspectives from theory and practice. London: Routledge.

Deakin Crick, R., Broadfoot, P., \& Claxton, G. (2004). Developing an effective lifelong learning inventory: The ELLI project. Assessment in Education, 11(3), 248-272.

Deakin Crick, R., \& Goldspink, C. (2014). Learner dispositions, self-theories and student engagement. British Journal of Educational Studies, 62(1), 19-35.

Deakin Crick, R., \& Grushka, K. (2010). Signs, symbols and metaphor: Linking self with text in inquiry based learning. Curriculum Journal, 21(1), 447-464.

Deakin Crick, R., Haigney, D., Huang, S., Coburn, T., \& Goldspink, C. (2013). Learning power in the workplace: The effective lifelong learning inventory and its reliability and validity and implications for learning and 
development. International Journal of Human Resource Management, 24, 2255-2272.

Deakin Crick, R., Huang, S., Ahmed Shafi, A., \& Goldspink, C. (2015). Developing resilient agency in learning: The internal structure of learning power. British Journal of Educational Studies, 63(2), 121-160.

Deakin Crick, R., \& Jelfs, H. (2011). Spirituality, learning and personalisation: Exploring the relationship between spiritual development and learning to learn in a faith-based secondary school. International Journal of Children's Spirituality, 16(3), 197-217.

Deakin Crick, R., Jelfs, H., Huang, S., \& Wang, Q. (2011). Learning futures final report. London: Paul Hamlyn Foundation.

Deakin Crick, R., Jelfs, H., Symonds, J., Ren, K., Grushka, K., Huang, S., Wang, Q., \& Varnavskaja, N. (2010). Learning futures evaluation report. University of Bristol, UK.

Deakin Crick, R., \& McCombs, B. (2006). The assessment of learner centred principles: An English case study. Eudcational Research and Evaluation, 12(5), 423-444.

Deakin Crick, R., McCombs, B., Broadfoot, P., Tew, M., \& Hadden, A. (2004). The ecology of learning: The ELLI two project report. Bristol, UK: Lifelong Learning Foundation.

Deakin Crick, R., McCombs, B., \& Haddon, A. (2007). The ecology of learning: Factors contributing to learner centred classroom cultures. Research Papers in Education, 22(3), 267-307.

Deakin Crick, R., \& Yu, G. (2008). Assessing learning dispositions: Is the effective lifelong learning inventory valid and reliable as a measurement tool? Educational Research, 50(4), 387-402.

Deci, E., \& Ryan, R. (1985). Intrinsic motivation and self-determination in human behaviour. New York: Plenum.

Dweck, C. S. (2000). Self-theories: Their role in motivation, personality, and development. New York: Psychology Press.

Godfrey, P., Deakin Crick, R., \& Huang, S. (2014). Systems thinking, systems design and learning power in engineering education. International Journal of Engineering Education, 30(1), 112-127.

Goldspink, C., \& Foster, M. (2013). A conceptual model and set of instruments for measuring student engagement in learning. Cambridge Journal of Education, 43(3), 291-311.

Goodson, I., \& Deakin Crick, R. (2009). Curriculum as narration: Tales from the children of the colonised. Curriculum Journal, 20(3), 225-236.

Grushka, K. (2009). Identity and meaning: A visual performative pedagogy for socio-cultural learning. Curriculum Journal, 20(3), 237-251.

Habermas, J. (1973). Knowledge and human interests. Cambridge, UK: Cambridge University Press.

Habermas, J. (1989). The theory of communicative action: The critique of functionalist reason, vol. 2. Cambridge, UK: Polity Press.

Harlen, W. (2004). A systematic review of the evidence of reliability and validity of assessment by teachers used for summative purposes. Research Evidence in Education Library, EPPI-Centre, Social Science Research Unit, Institute of Education, London.

Harlen, W., \& Deakin Crick, R. (2002). A systematic review of the impact of summative assessment and testing on pupils' motivation for learning. Evidence for Policy and Practice Co-ordinating Centre, Department for Education and Skills, London.

Harlen, W., \& Deakin Crick, R. (2003). Testing and motivation for learning. Assessment in Education, 10(2), 169-207.

Huang, S. (2014). Imposed or emergent? A critical exploration of authentic pedagogy from a complexity perspective. University of Bristol, UK.

Jacobi, J. (1980). The psychology of C. G. Jung. London: Routledge \& Kegan Paul. 
John-Steiner, V. (2000). Creative collaboration. Oxford, UK: Oxford University Press.

John-Steiner, V., Panofsky, C., \& Smith, L. (1994). Socio-cultural approaches to language and literacy: An interactionist perspective. New York: Cambridge University Press.

Kelly, G. A. (1963). A theory of personality. New York: Norton.

Laloux, F. (2015). Reinventing organisations: A guide to creating organizations inspired by the next stage of human consciousness. Nelson Parker.

Long, P., \& Siemens, G. (2011). Penetrating the fog: Learning analytics and education. Educause Review, September/October, 31-40. https://net.educause.edu/ir/library/pdf/ERM1151.pdf

Morin, E. (2008). On complexity. New York: Hampton Press.

Outhwaite, W. (1994). Habermas: A critical introduction. Cambridge, UK: Polity Press.

Ren, K. (2010). "Could do better, so why not?" Empowering underachieving adolescents. University of Bristol, UK.

Ren, K., \& Deakin Crick, R. (2013). Empowering underachieving adolescents: An emancipatory learning perspective on underachievement. Pedagogies: An International Journal, 8(3), 235-254.

Rutter, M. (2012). Resilience as a dynamic concept. Development and Psychopathology, 24, 335-344.

Seely Brown, J. (2015). Re-imagining libraries and learning for the 21 century. Aspen Institute Roundtable on Library Innovation, 10 August 2015, Aspen, Colorado. http://www.johnseelybrown.com/reimaginelibraries. pdf

Seely Brown, J., \& Thomas, D. (2009). Learning for a world of constant change. Paper presented at the $7^{\text {th }}$ Gillon Colloquium, University of Southern California.

Seely Brown, J., \& Thomas, D. (2010). Learning in/for a world of constant flux: Homo sapiens, homo faber \& homo ludens revisited. In L. Weber \& J. J. Duderstadt (Eds.), University Research for Innovation: Glion VII Colloquium (pp. 321-336). Paris: Economica.

Selvin, A., \& Buckingham Shum, S. (2014). Constructing knowledge art: An experiential perspective on crafting participatory representations. San Rafael CA: Morgan \& Claypool.

Sillitto, H. (2015). Architecting systems: Concepts, principles and practice. London: College Publications Systems Series.

Simsek, D., Sandor, A., Buckingham Shum, S., Ferguson, R., De Liddo, A., \& Whitelock, D. (2015). Correlations between automated rhetorical analysis and tutors' grades on student essays. Proceedings of the $5^{\text {th }}$ International Conference on Learning Analytics and Knowledge (LAK '15), 16-20 March 2015, Poughkeepsie, NY, USA (pp. 355-359). New York: ACM. doi:10.1145/2723576.2723603

Snowden, D., \& Boone, M. E. (2007, November). A leader's framework for decision making. Harvard Business Review. https://hbr.org/2007/11/a-leaders-framework-for-decision-making

Thomas, D., \& Seely Brown, J. (2011). A new culture of learning: Cultivating the imagination for a world of constant change. CreateSpace Independent Publishing Platform.

Wang, Q. (2013). Coaching psychology for learning: A case study of enquiry based learning and learning power development in secondary education in the UK. University of Bristol, UK.

Wertsch, J. (1985). Vygotsky and the social formation of mind. Cambridge, MA: Harvard University Press.

Willis, J. (2014). Learning to learn with indigenous Australians. In R. Deakin Crick, C. Stringher, \& K. Ren (Eds.), Learning to learn: International perspectives from theory and practice (pp. 306-327). London: Routledge.

Yeager, D., Bryk, A., Muhich, J., Hausman, H., \& Morales, L. (2013, December). Practical measurement. San Francisco, CA: Carnegie Foundation for the Advancement of Teaching. https://www.carnegiefoundation.org/ resources/publications/practical-measurement/ 


\section{APPENDIX I}

\section{learning emergence}

CLARA Group Overview

Creation Date: 19 May 2016

Group Name: Class Room - 4 A

\section{Here is the collective Learning Power Profile of Class Room - 4 A}
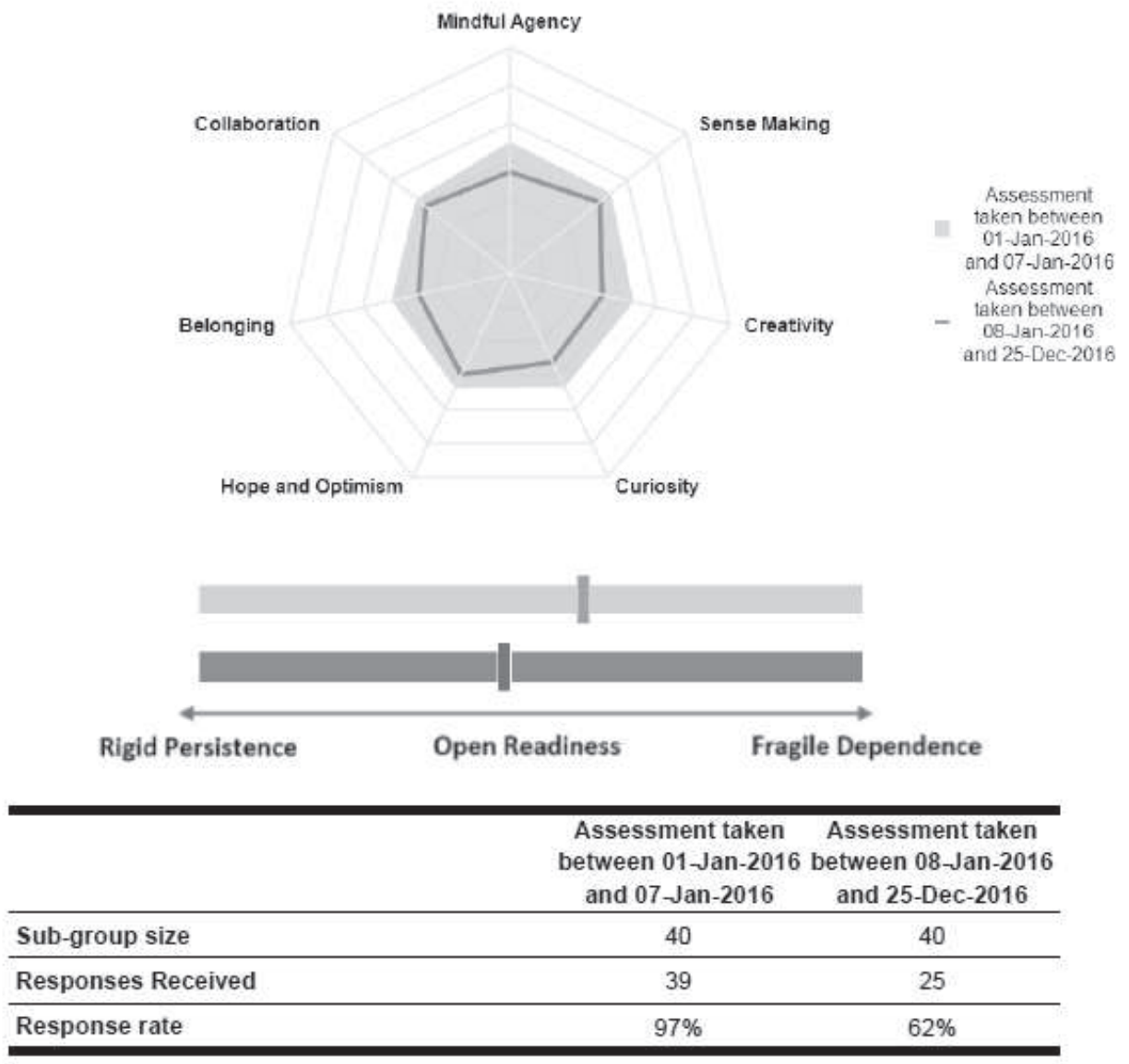

CLARA Group Overview for Class Room - 4 A 
The histograms below compare the score distribution in the first and second assessment in each of the eight CLARA dimensions:

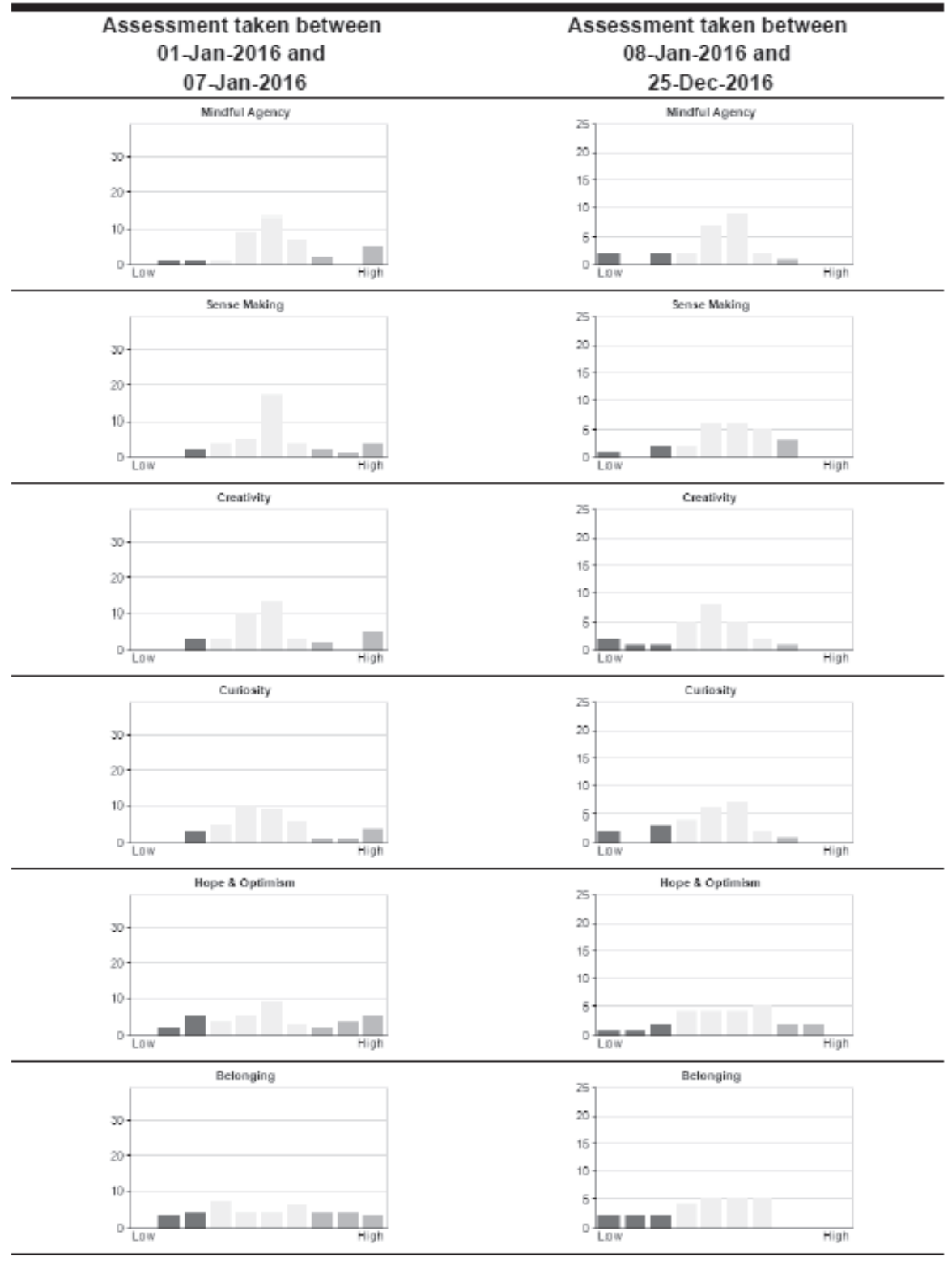

CLARA Group Overview for Class Room - 4 A

Report Generated on 19 May 2016 


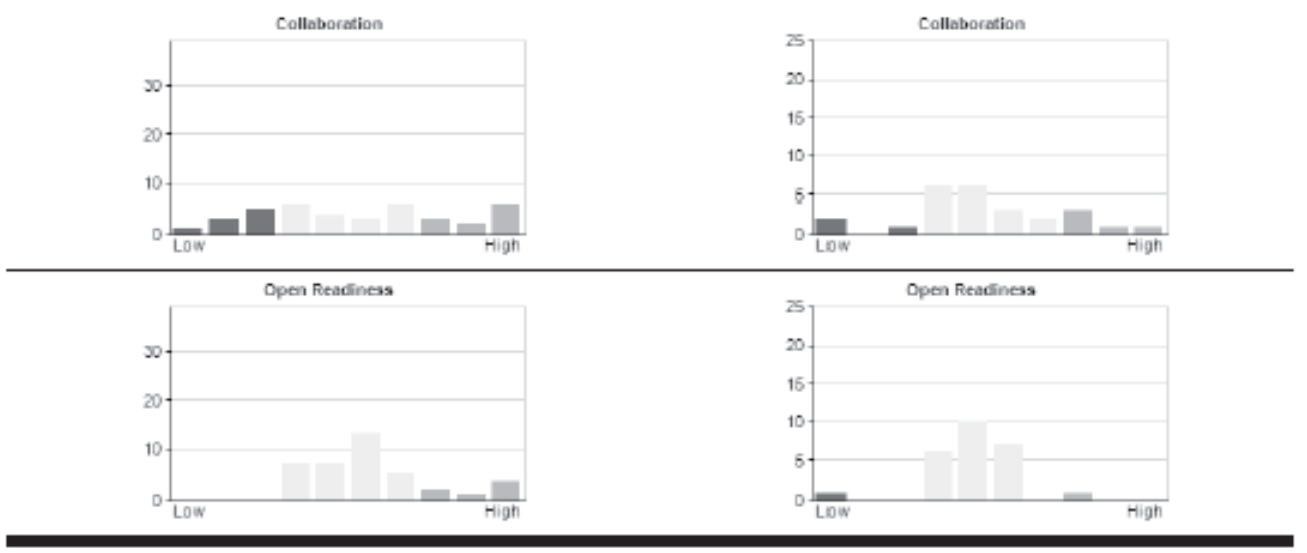

This table below compares numerically the score distributions in the first and the second assessment oh this group:

\begin{tabular}{|c|c|c|c|c|c|c|}
\hline CLARA Dimension & Assessment & $\mathrm{N}$ & Min. & Max. & Mean & S.D. \\
\hline \multirow{2}{*}{ Belonging } & 1 & 39 & 12.28 & 100.00 & 53.77 & 24.30 \\
\hline & 2 & 25 & 0.00 & 69.18 & 41.32 & 19.53 \\
\hline \multirow{2}{*}{ Collaboration } & 1 & 39 & 4.42 & 100.00 & 53.26 & 27.88 \\
\hline & 2 & 25 & 0.00 & 95.58 & 47.84 & 23.01 \\
\hline \multirow{2}{*}{ Creativity } & 1 & 39 & 26.22 & 100.00 & 56.17 & 19.78 \\
\hline & 2 & 25 & 0.00 & 74.46 & 42.29 & 18.21 \\
\hline \multirow{2}{*}{ Curiosity } & 1 & 39 & 26.90 & 100.00 & 55.85 & 19.60 \\
\hline & 2 & 25 & 0.00 & 74.48 & 43.44 & 18.14 \\
\hline \multirow{2}{*}{ Hope and Optimism } & 1 & 39 & 13.72 & 100.00 & 56.17 & 24.73 \\
\hline & 2 & 25 & 0.00 & 86.28 & 49.30 & 21.17 \\
\hline \multirow{2}{*}{ Mindful Agency } & 1 & 39 & 16.50 & 99.88 & 58.44 & 19.16 \\
\hline & 2 & 25 & 0.00 & 77.62 & 44.90 & 18.29 \\
\hline \multirow{2}{*}{ Orientation to Learning } & 1 & 39 & 30.36 & 100.00 & 56.93 & 18.93 \\
\hline & 2 & 25 & 0.00 & 79.44 & 44.84 & 13.46 \\
\hline \multirow{2}{*}{ Sense Making } & 1 & 39 & 27.32 & 100.00 & 57.21 & 19.13 \\
\hline & 2 & 25 & 0.00 & 76.06 & 50.85 & 17.38 \\
\hline
\end{tabular}

1=Assessment taken between 01-Jan-2016 and 07-Jan-2016

2=Assessment taken between 08-Jan-2016 and 25-Dec-2016

$\mathrm{N}=$ Response Received

Min.= the lowest score reported

Max. $=$ the highest score reported

S.D. = standard deviation of the score distribution 